\title{
Magnetic Amphiphilic Composites Based on Carbon Nanotubes and Nanofibers Grown on an Inorganic Matrix: Effect on Water-Oil Interfaces
}

\author{
Aline A. S. Oliveira, ${ }^{a}$ Ivo F. Teixeira, ${ }^{a}$ Leandro P. Ribeiro, ${ }^{a}$ Juliana C. Tristão, ${ }^{a}$ \\ Anderson Dias ${ }^{b}$ and Rochel M. Lago ${ }^{*, a}$ \\ ${ }^{a}$ Departamento de Química, Universidade Federal de Minas Gerais, \\ 31270-901 Belo Horizonte-MG, Brazil \\ ${ }^{b}$ Departamento de Química, Universidade Federal de Ouro Preto, \\ 35400-000 Ouro Preto-MG, Brazil
}

\begin{abstract}
Novos compósitos magnéticos anfifílicos foram preparados pelo crescimento de nanotubos e nanofibras de carbono contendo partículas magnéticas através de deposição química de vapor (CVD), utilizando etanol como fonte de carbono e lama vermelha (RM, subproduto do processo Bayer de produção de alumina) como suporte e catalisador. Monitoramento da reação CVD à temperatura programada (TPCVD), difração de raios X (XRD), espectroscopia Mössbauer, espectroscopia de energia dispersiva (EDS), espectroscopia Raman, termogravimetria (TG/DTA), análise elementar $(\mathrm{CHN})$, determinação de área superficial (BET), microscopia eletrônica de varredura (SEM) e de transmissão (TEM) e medidas magnéticas mostraram que etanol reduz íons de ferro na RM para formar fases magnéticas, por exemplo $\mathrm{Fe}_{3} \mathrm{O}_{4}$ e $\mathrm{Fe}^{0}$, e depósitos de carbono (5-42 wt.\%) na forma de nanotubos e nanofibras. A combinação de nanoestruturas hidrofóbicas de carbono com óxidos hidrofílicos de Al, Si e Ti presentes na lama vermelha produziu materiais anfifílicos com excelente interação com a interface água-óleo. Misturas de óleo de soja ou de decalina com água (completamente imiscíveis) foram emulsificadas facilmente na presença dos compósitos anfifílicos. Quando os compósitos foram adicionados a uma emulsão água-biodiesel estável, as partículas anfifílicas difundiram-se para a interface água- óleo. As partículas do compósito foram atraídas por ímãs e carregaram com elas as gotas de óleo, levando à completa desemulsificação e separação entre biodiesel e água.
\end{abstract}

New magnetic amphiphilic composites were prepared by the catalytic carbon vapor deposition (CVD) growth of carbon nanotubes and nanofibers using ethanol as carbon source and red mud waste (RM, a by-product of the Bayer process of alumina production) as catalyst and support. Temperature-programmed CVD (TPCVD), analyses by X-ray diffractometry (XRD), Mössbauer spectroscopy, energy dispersive X-ray spectroscopy (EDS), Raman spectroscopy, thermogravimetry (TG/DTA), elemental analysis (CHN), superficial area determination (BET), scanning (SEM) and transmission (TEM) electron microscopies and magnetic measurements showed that ethanol reduces the iron ions in the red mud to form magnetic phases, e.g., $\mathrm{Fe}_{3} \mathrm{O}_{4}$ and $\mathrm{Fe}^{0}$, and carbon deposits (5-42 wt.\%), particularly nanotubes and nanofibers. The combination of the hydrophobic carbon nanostructures with the hydrophilic $\mathrm{Al}, \mathrm{Si}$ and Ti oxides present in the RM produced amphiphilic materials with excellent interaction with the water-oil interface. Soybean oil or decalin mixtures with water (completely immiscible) were easily emulsified in the presence of the amphiphilic composites. When the composites were added to stable biodiesel-water emulsions, the amphiphilic particles diffused to the interface oil-water. These composite particles were attracted by a magnet, carrying the oil droplets with them and leading to the complete demulsification and separation of the biodiesel from the water.

Keywords: red mud, amphiphilic composites, emulsification, demulsification

*e-mail: rochel@ufmg.br 


\section{Introduction}

Red mud (RM) is a waste generated in the Bayer process, with 90 million ton/year worldwide and 20 million ton/year only in Brazil. ${ }^{1}$ It has found limited destination in low value applications such as road making, land reclamation and cement production. ${ }^{2}$ On the other hand, the RM composition, mainly $\mathrm{Fe}, \mathrm{Al}, \mathrm{Si}$, Ti, $\mathrm{Na}, \mathrm{Ca}$ and $\mathrm{Mg}$ oxides, ${ }^{3}$ offers different possibilities of application such as recovery of metals, ${ }^{1,4}$ ceramic production, ${ }^{5}$ water treatment (removal of phenol, ${ }^{6}$ heavy metals ${ }^{7,8}$ nitrate, ${ }^{9}$ phosphate, ${ }^{10}$ dyes $\left.{ }^{11}\right)$, treatment of acid mine drainage, ${ }^{12}$ hydrodechlorination, ${ }^{13}$ production of X-ray shielding materials, ${ }^{14}$ corrosion inhibition, ${ }^{15}$ production of composites with polymers, ${ }^{16}$ production of hydrogen, ${ }^{17}$ catalysis, ${ }^{18} \mathrm{CO}_{2}$ sequestration ${ }^{19}$ and production of coagulants. ${ }^{20,21}$

In this contribution, a novel application of RM is suggested, i.e., production of amphiphilic magnetic composites with carbon nanofibers/nanotubes. Red mud has thermally stable oxides, e.g., $\mathrm{Al}_{2} \mathrm{O}_{3}, \mathrm{SiO}_{2}$ and $\mathrm{TiO}_{2}$, which can play two important roles: to disperse the $\mathrm{Fe}$ phases for the chemical vapor deposition (CVD) reaction and to contribute to the amphiphilic character of the product with their hydrophilic surfaces. Upon CVD using ethanol as carbon source, large particles of iron oxy-hydroxides are reduced to form large $\mathrm{Fe}^{0}$ particles (encapsulated with carbon), responsible for the magnetic properties of the composite. More dispersed iron in the RM is reduced to $\mathrm{Fe}^{0}$ and catalyze the formation, by CVD, of high surface area hydrophobic carbon nanotubes and nanofibers from the alcohol.

An important application of these magnetic amphiphilic composites is in the emulsification and demulsification of oil-water systems. These processes are used in different areas such as fine chemicals, pesticides, essential oils and flavors, pharmaceuticals, laundries, effluent treatment and environmental processes. ${ }^{22-27}$ Commercial demulsifiers are based on amphiphilic polymers which cannot be recovered and remain as contaminants in downstream processes. ${ }^{28}$

Herein, a completely new family of reusable emulsifier/ demulsifiers based on nanostructured magnetic amphiphilic composites is described. These composites show several important advantages, e.g., are produced from a waste, can be magnetically recovered and reused several times, do not contaminate the treated emulsion and are an example of the application of nanotechnology.

\section{Experimental}

The raw RM waste was obtained from ALCAN Brazil and extensively washed with water and dried at $80^{\circ} \mathrm{C}$ before use. This purified RM was analyzed by atomic absorption spectroscopy to determine the content of the main components.

The temperature-programmed chemical vapor deposition (TPCVD) studies were carried out with ethanol at $c a .6 \mathrm{vol} \%$ in $\mathrm{N}_{2}\left(30 \mathrm{~mL} \mathrm{~min}^{-1}\right)$ and $50 \mathrm{mg}$ of red mud in a quartz tube of $7 \mathrm{~mm}$ diameter placed in the central part of the oven and heated at $5{ }^{\circ} \mathrm{C} \mathrm{min}-1$ up to $950{ }^{\circ} \mathrm{C}$. The reaction was interrupted at different temperatures, i.e., 500, 600, 700, 800, 900 and $950^{\circ} \mathrm{C}\left(700{ }^{\circ} \mathrm{C}\right.$ for 1 and $\left.3 \mathrm{~h}\right)$. The reaction products were analyzed online by gas chromatography (Shimadzu GC17A GC equipped with a FID detector and a Carbowax capillary column). The samples were characterized by EDS microanalysis, powder XRD, Mössbauer spectroscopy, magnetization measurements, TG/DTA, Raman spectroscopy, BET surface area determination, SEM and TEM.

The powder XRD data were obtained with a Rigaku model Geigerflex equipment using $\mathrm{CoK}_{\alpha}$ radiation and scanning from 10 to $80^{\circ}(2 \theta)$ at a scan rate of $4^{\circ} \mathrm{min}^{-1}$. Silicon was used as an external standard. The crystallite sizes were determined by the use of Scherrer's equation. The transmission Mössbauer spectroscopy experiments were carried out in a CMTE model MA250 spectrometer with a ${ }^{57} \mathrm{Co} / \mathrm{Rh}$ source at room temperature, using $\alpha$-Fe as a reference. The magnetization measurements were carried out in a portable magnetometer with a fixed magnetic field of $0.3 \mathrm{~T}$. Thermogravimetric analyses were carried out with a Shimadzu TGA-60 equipment, with a constant heating rate of $10{ }^{\circ} \mathrm{C} \mathrm{min}^{-1}$ under air flow $\left(100 \mathrm{~mL} \mathrm{~min}^{-1}\right)$. Raman spectroscopy was carried out using a Horiba/JobinYvonLABRAM-HR spectrometer with the $632.8 \mathrm{~nm}$ line of a helium-neon laser. The surface area was determined by nitrogen adsorption using the BET method with $22 \mathrm{~N}_{2}$ adsorption/desorption cycles in an Autosorb 1 Quantachrome instrument. SEM analysis was performed using a Jeol JSM 840A and a Quanta 200 ESEM FEG from FEI, while TEM was performed with a Tecnai G2-20 microscope from FEI.

Demulsification tests were carried out with a biodiesel/ water $(30 \% \mathrm{v} / \mathrm{v})$ emulsion prepared from methyl soybean biodiesel. The mixture was homogenized in a magnetic stirrer at ca. $1000 \mathrm{rpm}$ for $10 \mathrm{~min}$. Emulsification tests were carried out with soybean oil/water $(25 \% \mathrm{v} / \mathrm{v})$ and decalin/water $(50 \% \mathrm{v} / \mathrm{v})$ emulsions. The mixtures were sonicated (Thornton T-14) for $1 \mathrm{~min}$ and the resulting emulsion was analyzed by optical microscopy (Cole Parmer Instrument, 41500-50). The amphiphilic composites were added to the systems in the concentration of 500 and $1000 \mathrm{mg} \mathrm{L}^{-1}$.

\section{Results and Discussion}

Chemical analysis of the RM used to prepare the composites by atomic absorption spectroscopy showed the 
presence of $\mathrm{Fe}_{2} \mathrm{O}_{3}(20 \%), \mathrm{Al}_{2} \mathrm{O}_{3}(22 \%), \mathrm{CaO}(5 \%), \mathrm{Na}_{2} \mathrm{O}$ $(6 \%), \mathrm{MnO}(0.4 \%), \mathrm{SiO}_{2}(11 \%)$ and $\mathrm{TiO}_{2}(3 \%)$ as the main components.

The reaction of ethanol with RM was studied by temperature-programmed CVD experiments (Figure S1, Supplementary Information). In the presence of RM, ethanol is gradually consumed from $380{ }^{\circ} \mathrm{C}$, reaching $90 \%$ conversion at approximately $470{ }^{\circ} \mathrm{C}$, while its thermal decomposition takes place only at $650{ }^{\circ} \mathrm{C}$. It is well known that the gas phase products formed are mainly $\mathrm{CO}_{x}$ and $\mathrm{H}_{2} \mathrm{O}$, although these oxidized phases cannot be identified by flame ionization detection (FID). By gas chromatography analyses with FID detector, traces of ethylene and acetaldehyde were identified. The CVD reactions were quenched at different temperatures, i.e., 500, $600,700,800,900$ and $950^{\circ} \mathrm{C}$ and named according to the temperature of reaction, i.e., $\mathrm{RmEt} 500$ produced at $500^{\circ} \mathrm{C}$. The composites were characterized by different techniques, such as Mössbauer spectroscopy, XRD, TG/DTA, BET surface area, Raman spectroscopy, SEM and TEM.

Mössbauer spectroscopy results (Figure S2) showed the presence of iron in the starting RM sample mainly as well crystallized hematite $\left(\mathrm{Fe}_{2} \mathrm{O}_{3}, 52 \%\right.$ relative area) and a highly dispersed $\mathrm{Fe}^{3+}$ superparamagnetic species $(48 \%)$. After reaction with ethanol at $500{ }^{\circ} \mathrm{C}$, several reduced iron phases are observed, i.e., magnetite $\left(\mathrm{Fe}_{3} \mathrm{O}_{4}, 55 \%\right)$, würstite $\left(\mathrm{Fe}_{1-\mathrm{x}} \mathrm{O}, 7 \%\right)$ and even metallic iron (8\%). Both $\mathrm{Fe}_{2} \mathrm{O}_{3}$ and dispersed $\mathrm{Fe}^{3+}$ can be reduced in a stepwise process by ethanol according to the simplified equation:

$\mathrm{Fe}^{3+}$ or $\mathrm{Fe}_{2} \mathrm{O}_{3} \rightarrow \mathrm{Fe}_{3} \mathrm{O}_{4} \rightarrow \mathrm{Fe}_{1-\mathrm{x}} \mathrm{O} \rightarrow \mathrm{Fe}^{0}$

Besides the reduced iron phases, iron carbide was also observed in RmEt600 (Figure 1). At $700{ }^{\circ} \mathrm{C}$, the phases $\mathrm{Fe}_{3} \mathrm{O}_{4}$ and $\mathrm{Fe}_{1-\mathrm{x}} \mathrm{O}$ are completely consumed to produce $\mathrm{Fe}^{0}$ and $\mathrm{Fe}_{3} \mathrm{C}$. At 800,900 and $950{ }^{\circ} \mathrm{C}$, similar results were obtained with the formation of $\mathrm{ca} .60 \% \mathrm{Fe}_{3} \mathrm{C}, 20 \%$ $\mathrm{Fe}^{0}$ and $20 \% \mathrm{Fe}^{3+}$ phases. The $\mathrm{Fe}^{3+}$ superparamagnetic phase in these materials is likely formed by the oxidation of $\mathrm{Fe}^{0}$ when the sample is exposed to air at room temperature.

$\mathrm{X}$-ray diffraction analysis confirmed the presence of $\alpha-\mathrm{Fe}_{2} \mathrm{O}_{3}, \mathrm{Al}_{2} \mathrm{O}_{3}, \mathrm{CaO}, \mathrm{SiO}_{2}$ and $\mathrm{Ti}_{2} \mathrm{O}_{3}$ in pure $\mathrm{RM}$ and also the conversion of hematite to magnetite after reaction with ethanol at 500 and $600{ }^{\circ} \mathrm{C}$. After TPCVD with ethanol at $700,800,900$ and $950{ }^{\circ} \mathrm{C}$, metallic iron $\left(\mathrm{Fe}^{0}\right)$, iron carbide $\left(\mathrm{Fe}_{3} \mathrm{C}\right)$ and graphitic carbon deposits were detected. The XRD results are shown in Figure S3.

All prepared materials became magnetic after TPCVD with ethanol with spontaneous magnetization values of 27 to 30 against $0.7 \mathrm{~J} \mathrm{~T}^{-1} \mathrm{~kg}^{-1}$ of pure RM.

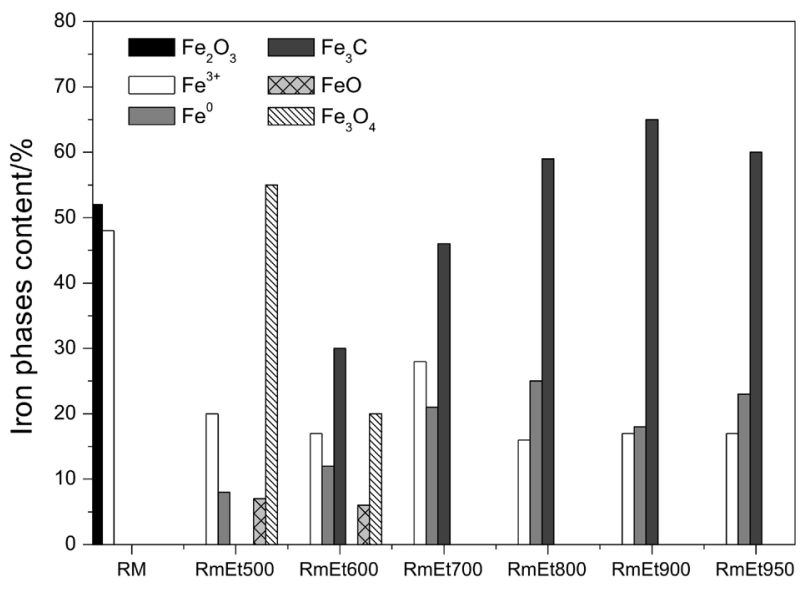

Figure 1. Mössbauer composition of the iron phases determined for pure $\mathrm{RM}$ and products of TPCVD with ethanol in different conditions.

Thermal analysis of the composites showed weight gains due to the oxidation of the reduced iron phases around $300{ }^{\circ} \mathrm{C}$. The carbon contents were estimated based on the weight losses by carbon oxidation from ca. 400 up to $500^{\circ} \mathrm{C}$. The obtained \%C for the samples prepared at 700,800 , 900 and $950{ }^{\circ} \mathrm{C}$ were $c a .27,30,32$ and $30 \%$, respectively. TG (Figure S4), DTG (Figure S5) curves and also further information about the results of thermogravimetric analyses are presented as SI.

Raman spectra of the obtained materials showed intense $\mathrm{D}$ and $\mathrm{G}$ bands at 1380 and $1600 \mathrm{~cm}^{-1}$, respectively (Figure S6). The D band suggests formation of more defective carbonaceous structures (such as amorphous carbon) and the $\mathrm{G}$ band the formation of graphitic carbon in the form of graphite and carbon nanotubes $(\mathrm{CNT}) .^{29} \mathrm{~A}$ series of bands related to different oxides, e.g., oxides of $\mathrm{Fe}, \mathrm{Si}, \mathrm{Al}$ and Ti present in $\mathrm{RM}$, can also be observed in the Raman spectral range of $100-1800 \mathrm{~cm}^{-1}$. Upon reaction with ethanol at $600{ }^{\circ} \mathrm{C}$, no significant change in these bands was observed. Upon reaction at $700{ }^{\circ} \mathrm{C}$ new bands at 147 and $205 \mathrm{~cm}^{-1}$ were registered, which are likely RBM modes ${ }^{30}$ related to the formation of single wall carbon nanotubes with estimated diameters of 1.0-1.6 nm. ${ }^{31}$ (Figure S7).

Surface area and pore size measurements (Figure S8) gave $10 \mathrm{~m}^{2} \mathrm{~g}^{-1}$ for the RM, which strongly increased after TPCVD at $600{ }^{\circ} \mathrm{C}\left(48 \mathrm{~m}^{2} \mathrm{~g}^{-1}\right)$ and $700{ }^{\circ} \mathrm{C}\left(79 \mathrm{~m}^{2} \mathrm{~g}^{-1}\right)$, likely due to the exposed area of the carbon deposits formed on the RM surface. At higher temperatures a slight decrease on the surface area was observed, which is likely related to sintering. Preliminary experiments showed that the material obtained at $700{ }^{\circ} \mathrm{C}$ can be activated with $\mathrm{CO}_{2}$ for $5 \mathrm{~h}$ at $750{ }^{\circ} \mathrm{C}$ producing a surface area of $c a .185 \mathrm{~m}^{2} \mathrm{~g}^{-1}$. The RM presents macropores with diameters over $50 \mathrm{~nm}$, while the sample RmEt700 presents mainly micro-mesopores smaller than $10 \mathrm{~nm}$. 
SEM (Figures S9 and S11) and TEM images (Figure 2) suggest the presence of irregular carbon nanofilaments which are likely responsible for increasing the surface area of the composites. The TEM and SEM images showed small nanometric Fe particles inside carbon filaments, while large metal aggregates appear covered with more amorphous carbon. The carbon filaments are on average $20 \mu \mathrm{m}$ long with diameters varying from 10 up to $100 \mathrm{~nm}$.

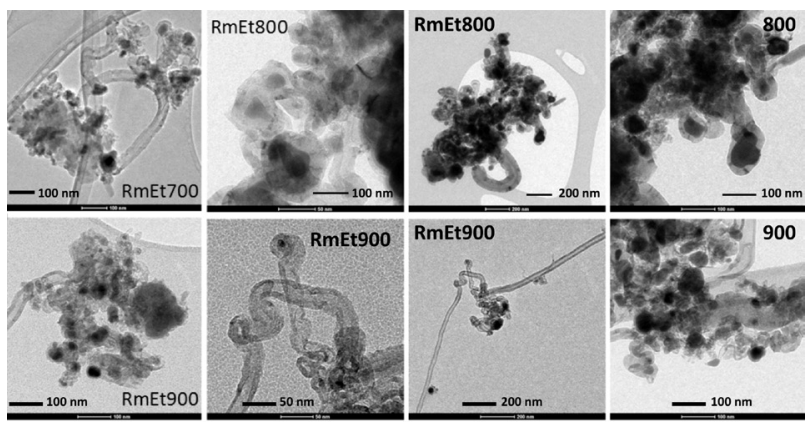

Figure 2. TEM images for RmEt 700, 800 and 900.

The effect of the magnetic amphiphilic particles was investigated in two immiscible mixtures, i.e., water/decalin and water/soybean oil. No emulsification took place in these mixtures even after sonication for $25 \mathrm{~min}$. On the other hand, in the presence of $1000 \mathrm{mg} \mathrm{L}^{-1}$ of the amphiphilic composite, the water/decalin and water/soybean oil mixtures emulsified after only $5 \mathrm{~min}$ sonication. The resulting emulsions are both of the oil-in-water $(\mathrm{o} / \mathrm{w})$ type emulsions.

Microscopic images taken from the water/soybean oil emulsion showed average emulsion droplet sizes of $c a$. $2 \mu \mathrm{m}$ in the presence of $\mathrm{RmEt} 700$. It was interesting to observe that for different composites the oil droplet changed with size, e.g., 5 and $10 \mu \mathrm{m}$ for emulsions obtained in the presence of RmEt700/1 $\mathrm{h}$ and 700/3 h, respectively. For the water/decalin emulsion, the average emulsion droplet sizes varied as 10 and $20 \mu \mathrm{m}$ for samples RmEt700 and $800^{\circ} \mathrm{C}$, respectively (Figures S19-S23). It is possible to observe that the composites with a higher carbon content promoted formation of larger emulsion droplets. In all cases, a simple approximation of a magnet to the sample attracted the composite particles leading to the coalescence of the oil droplets and the separation of the oil and water phases.

The amphiphilic composites can also be used to break stable emulsions. For example, during biodiesel washing (purification) procedures, the formation of stable emulsions of methyl and ethyl esters in water is relatively common due to the presence of soaps produced during the transesterification process. A stable emulsion of $30 \%$ soybean methyl biodiesel in water was stirred with $1000 \mathrm{mg} \mathrm{L}^{-1}$ of the amphiphilic composites during $5 \mathrm{~min}$. Microscopic analyzes showed that the composite particles were preferentially located at the oil-water interface. Under static conditions the emulsion is broken slowly and the composite remains dispersed throughout the medium. In the presence of a magnet, the composite particles are attracted and agglomerate rapidly, favoring the coalescence of the droplets and, consequently, the separation of aqueous and oily phases. This process usually takes 4-6 min to be completed with the concentration of $1000 \mathrm{mg} \mathrm{L}^{-1}$ of the composites (Figure 3). A small part of the volume that remains emulsified, between 20-30 vol\%, disappears gradually within $1 \mathrm{~h}$.

Figure 3 illustrates the processes involved in the emulsion breakdown.

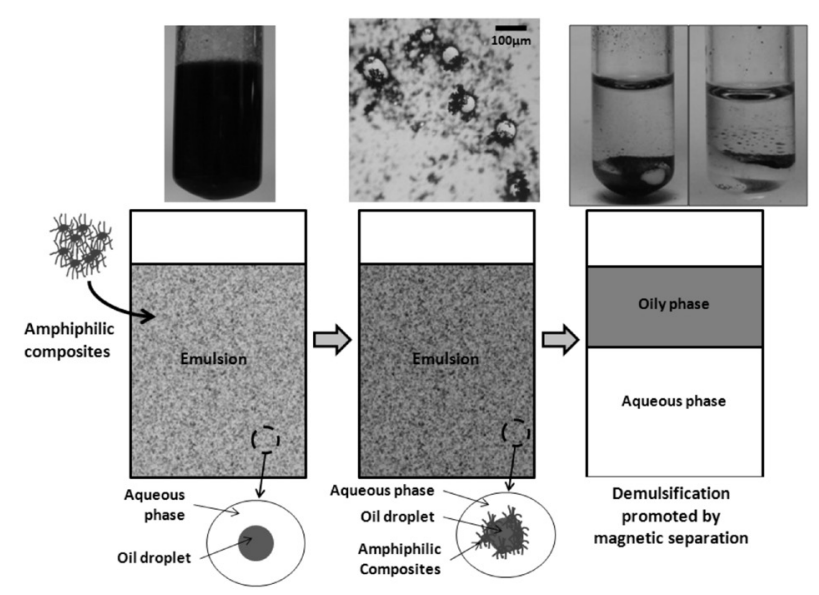

Figure 3. Demulsification promoted by the amphiphilic magnetic composites produced from RM.

The composites RmEt700 and 900 showed very good demulsification results even at lower concentrations, e.g., $500 \mathrm{mg} \mathrm{L}^{-1}$. The composite particles used can be easily recovered and reused for at least five times with the same efficiency.

\section{Conclusions}

The magnetic demulsifiers/emulsifiers produced in this work are a novel application of carbon-based nanostructured materials. These magnetic composites show several advantages over the commercially available products, e.g., (i) they are produced from a widely available waste, (ii) the synthesis can be tuned to produce more or less hydrophobic composites specific for different applications, (iii) they can be removed from the medium by a simple magnetic separation and reused several times with the same efficiency, (iv) they prevent the formation of lees after use, $(v)$ they do not contaminate either the aqueous or oily phases. 


\section{Supplementary Information}

Supplementary information (Figures S1-S23) is available free of charge at http://jbcs.sbq.org.br, as a PDF file.

\section{Acknowledgments}

The authors acknowledge the support of FAPEMIG, CNPq and FINEP. Thanks for the microscopic images provided by the UFMG Microscopy Center.

\section{References}

1. Kumar, S.; Kumar, R.; Bandopadhyay, A.; Resour. Conserv. Recycl. 2006, 48, 301.

2. Wang, S.; Ang, H.M.; Tadé, M. O.; Chemosphere 2008, 72, 1621.

3. Agrawal, K.; Sahu, K.; Pandey, B. D.; Resour. Conserv. Recycl. 2004, 42, 99.

4. Liu, W. C.; Yang, J. K.; Xiao, B.; J. Hazard. Mater. 2009, 161, 474.

5. Pontikes, Y.; Angelopoulos, G. N.; Adv. Appl. Ceram. 2009, 108, 50 .

6. Lin, S. H.; Juang, R. S.; J. Environ. Manag. 2009, 90, 1336.

7. Costa, E. T. D.; Guilherme, L. R. G.; Curi, N.; de Oliveira, L. C. A.; Visioli, E. L.; Lopes, G.; Rev. Bras. Cienc. Solo 2008, 32, 2533.

8. Santona, L.; Castaldi, P.; Melis, P.; J. Hazard. Mater. 2006, 136, 324.

9. Cengeloglu, Y.; Tor, A.; Erzöz, M.; Arslan, G.; Sep. Purif. Technol. 2006, 51, 374

10. Li, Y.; Liu, C.; Luan, Z.; Peng, X. ; Zhu, C.; Chen, Z. ; Zhang, Z.; Fan, J. ; Jia, Z.; J. Hazard. Mater. 2006, 137, 374.

11. Wang, S.; Boyjoo, Y.; Choueib, A.; Zhu, Z. H.; Water Res. 2005 , 39, 129.

12. Tuazon, D.; Corder, G. D.; Resour. Conserv. Recycl. 2008, 52, 1307.

13. Halász, J.; Hodos, M.; Hannus, I.; Tasi, G.; Kiricsi, I.; Colloids Surf., A 2005, 265, 171.

14. Amritphale, S. S.; Anshul, A.; Chandra, N.; Ramakrishnan, N.; J. Eur. Ceram. Soc. 2007, 27, 1945.
15. Collazo, A.; Fernández, D.; Izquierdo, M.; Nóvoa, X. R.; Pérez, C.; Prog. Org. Coat. 2005, 52, 351.

16. Akbulut, H.; Akinci, A.; Yimaz, E.; Polym. Polym. Compos. 2008, 16, 439.

17. Balakrishnan, M.; Batra, V. S.; Hargreaves, J. S. J.; Monaghan, A.; Pulford, I. D.; Rico, J. L.; Sushil, S.; Green Chem. 2009, 11,42 .

18. Sushil, S.; Batra, V. S.; Appl. Catal., B 2008, 81, 64.

19. Bonenfant, D.; Kharoune, L.; Sauve, S.; Hausler, R. ; Niquette, P. ; Mimeault, M. ; Kharoune, M.; Indian Chem. Eng. 2008, 47, 7617.

20. Krimpalis, S.; Papadopoulos, N.; Efthimiadis, K. G.; Karagianni, C. S.; Hristoforou, E.; J. Optoelectron. Adv. Mater. 2008, 10, 1085.

21. Wang, S. B.; Ang, H. M.; Tade, M. O.; Chemosphere 2008, 72, 1621.

22. Al-Sabagh, A. M.; Badawi, A. M.; Noor El-Din, M. R.; Pet. Sci. Technol. 2002, 20, 887.

23. Al-Sabagh, A. M.; Nehal, S. A.; Amal, M. N.; Gabr, M. M.; Colloids Surf., A. 2003, 216, 9.

24. Al-Sabagh, A. M.; Noor El-Din, M. R.; Mohamed, H. M.; Egyptian Journal of Petroleum 2006, 15, 49.

25. Al-Sabagh, A. M.; Maysour, N. E.; NoorEl-Din, M. R.; J. Dispersion Sci. Technol. 2007, 28, 547.

26. Oliveira. A. G.; Scarpa, M. V.; Correa, M. A.; Cera, L. F. R.; Formariz, T. P. Quim. Nova 2004, 27, 131.

27. Barros, F. F. C.; Quadros, C. P.; Maróstica Júnior, M. R.; Pastore, G. M.; Quim. Nova 2007, 30, 409.

28. Al-Sabagh, A. M.; NoorEl-Din, M. R.; Abo-ElFotouh, S.; Nasser, N. M.; J. Dispersion Sci. Technol. 2009, 30, 266.

29. Jorio, A., Pimenta, M. A.; Souza Filho, A. G.; Saito, R.; Dresselhaus, G.; Dresselhaus, M. S.; New J. Phys. 2003, 5, 139.

30. Jorio, A.; Saito, R.; Hafner, J. H.; Lieber, C. M.; Hunter, M.; McClure, T.; Dresselhaus, G.; Dresselhaus, M. S.; Phys. Rev. Lett. 2001, 86, 1118.

31. Araujo, P. T.; Maciel, I. O.; Pesce, P. B. C.; Pimenta, M. A.; Doorn, S. K.; Qian, H. ; Hartschuh, A.; Steiner, M.; Grigorian, L.; Hata, K.; Jorio, A.; Phys. Rev., B 2008, 77, 241403(R).

Submitted: May 28, 2010 Published online: October 7, 2010 


\section{Magnetic Amphiphilic Composites Based on Carbon Nanotubes and Nanofibers Grown on an Inorganic Matrix: Effect on Water-Oil Interfaces}

\section{Aline A. S. Oliveira, ${ }^{a}$ Ivo F. Teixeira, ${ }^{a}$ Leandro P. Ribeiro, ${ }^{a}$ Juliana C. Tristão, ${ }^{a}$} Anderson Dias ${ }^{b}$ and Rochel M. Lago ${ }^{*, a}$

${ }^{a}$ Departamento de Química, Universidade Federal de Minas Gerais, 31270-901 Belo Horizonte-MG, Brazil

${ }^{b}$ Departamento de Química, Universidade Federal de Ouro Preto, 35400-000 Ouro Preto-MG, Brazil

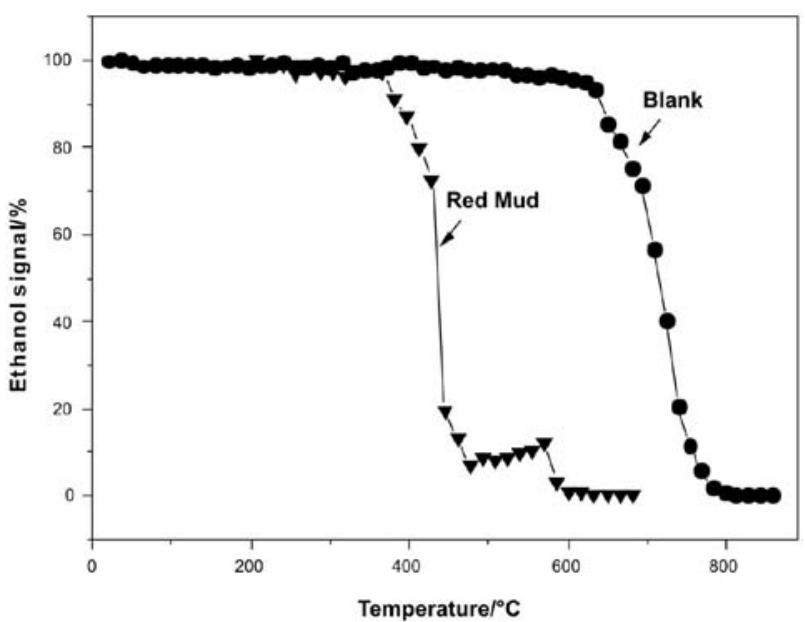

Figure S1. TPCVD profile for the reaction of red mud (RM) with ethanol.

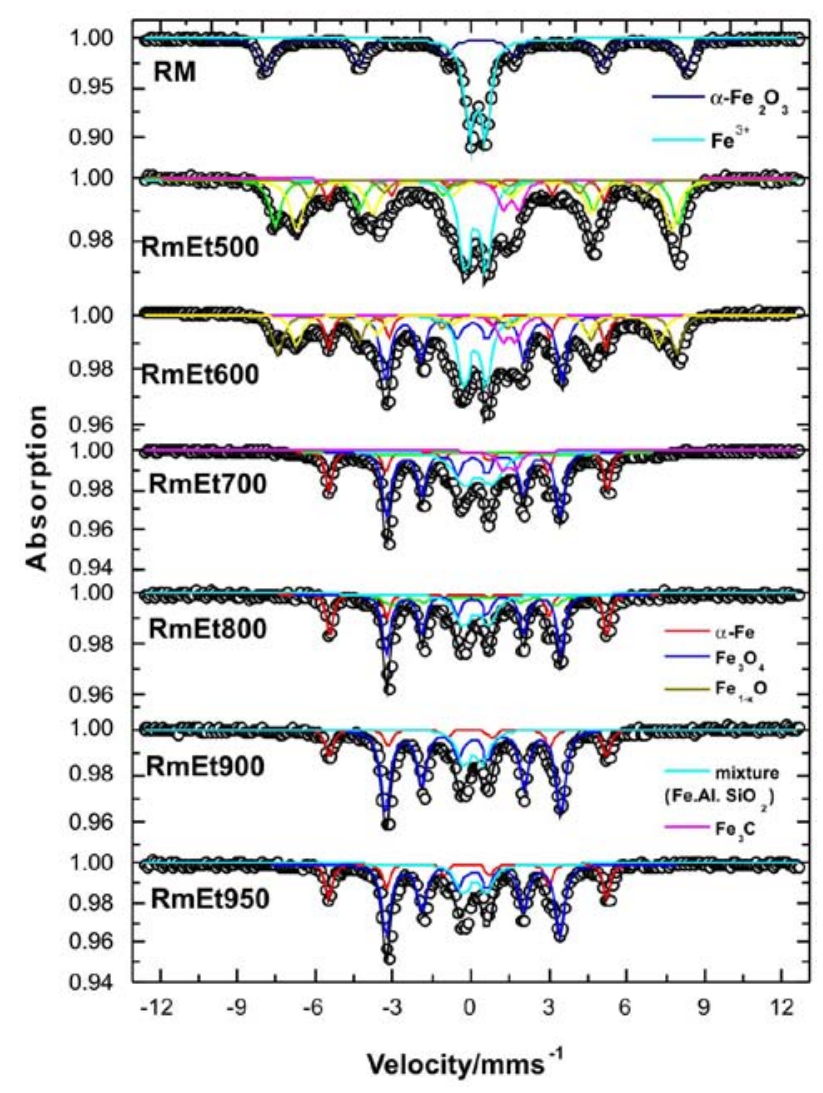

Figure S2. Mössbauer spectra (298 K) registered for pure red mud and the products of TPRe (RmEt) at 500, 600, 700, 800, 900 and $950{ }^{\circ} \mathrm{C}$. 


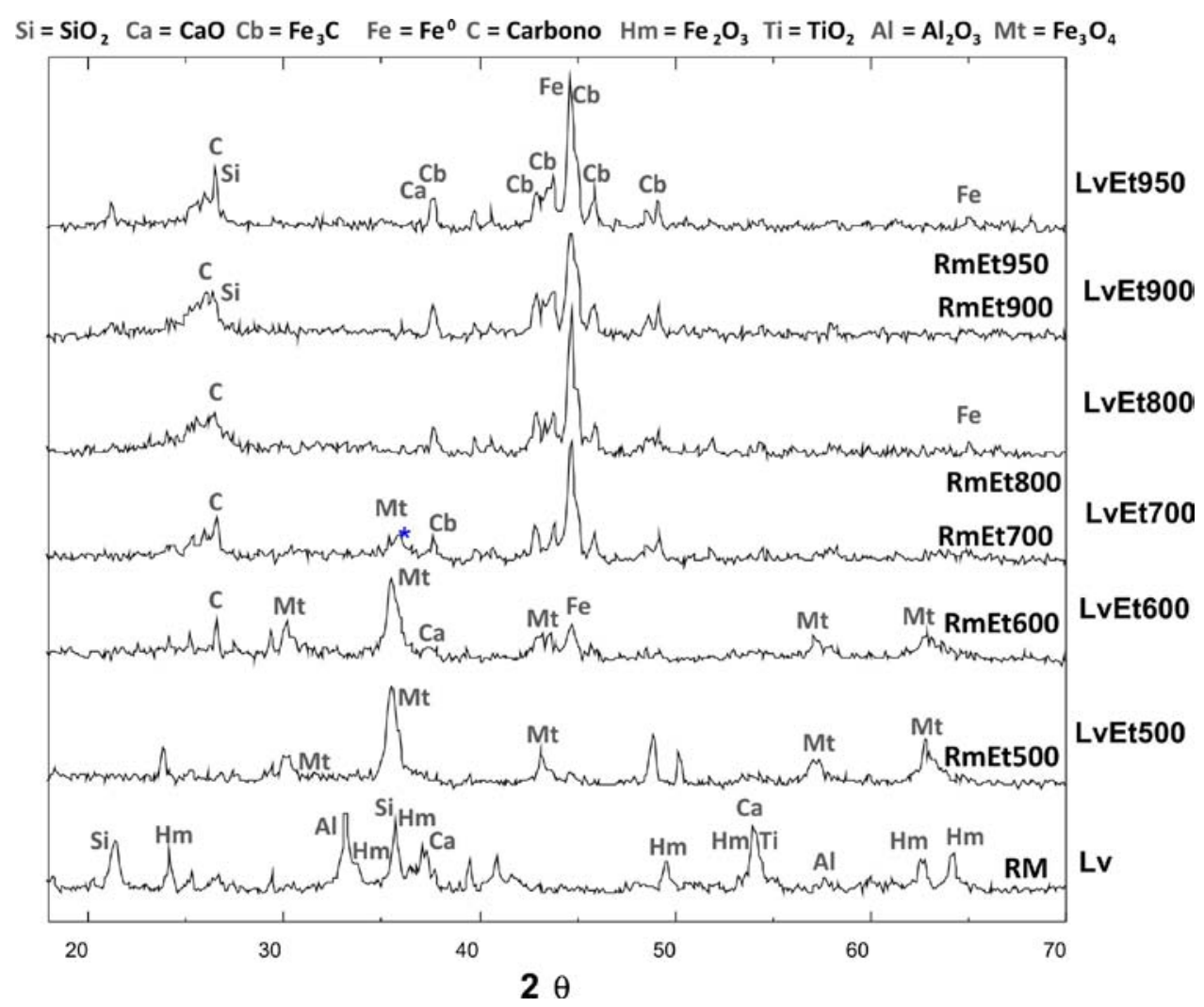

Figure S3. XRD results for RM and the materials prepared at different temperatures.

$\mathrm{XRD}$ analyses shown in Figure $\mathrm{S} 3$ showed the presence of $\alpha-\mathrm{Fe}_{2} \mathrm{O}_{3}, \mathrm{Al}_{2} \mathrm{O}_{3}, \mathrm{CaO}, \mathrm{SiO}_{2}$ and $\mathrm{Ti}_{2} \mathrm{O}_{3}$ in the pure red mud.

All prepared materials became strongly magnetic after TPCVD with ethanol with spontaneous magnetization values of 27 to $30 \mathrm{JT}^{-1} \mathrm{~kg}^{-1}$, while the pure red mud presents a magnetization value of $0.7 \mathrm{JT}^{-1} \mathrm{~kg}^{-1}$.

Thermal analyses were also carried out to characterize carbon deposits formed after TPCVD with ethanol. Figure S4 shows TG curves obtained for pure RM and for the samples RmEt700, 800, 900 and 950.

The TG curves showed a mass increase around 300 ${ }^{\circ} \mathrm{C}$. This increase is likely related to the oxidation of the reduced iron phases which appears in the DTA as an exothermic event. A strong weight loss is also observed from $c a .400$ up to $500{ }^{\circ} \mathrm{C}$, related to the oxidation of carbon deposits. From these weight losses the carbon content of the composites was estimated. The carbon contents obtained from TG and elemental analyses are shown in Figure 5 in detail. The obtained $\% \mathrm{C}$ for the samples prepared at $700,800,900$ e $950^{\circ} \mathrm{C}$ were $c a .27$, 30,32 and $30 \%$, respectively. The TG derivative curves (Figure S5) showed the presence of enlarged peaks with shoulders in $450{ }^{\circ} \mathrm{C}$, indicating the formation of different forms of carbon, such as amorphous and more organized carbon, e.g., graphitic structures.

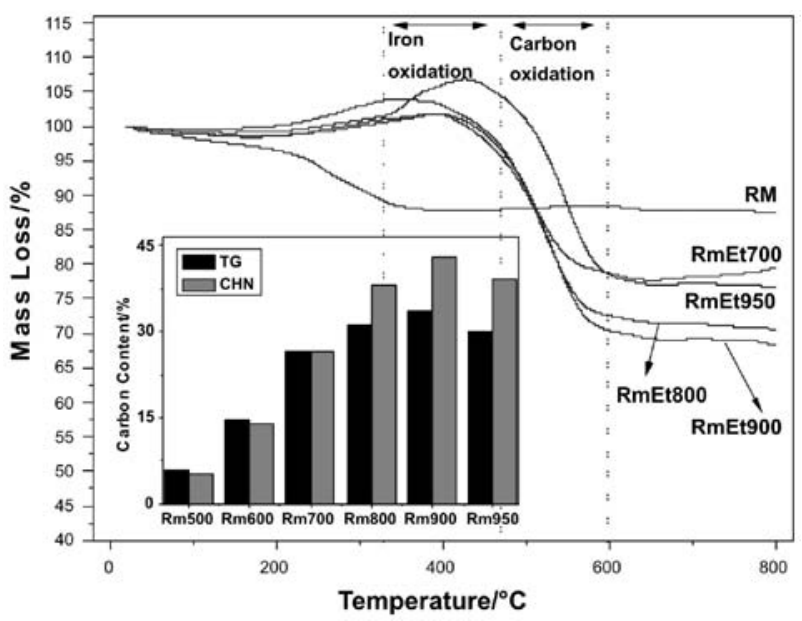

Figure S4. TG curves and carbon contents calculated for the composite materials based on TG and $\mathrm{CHN}$ results.

Raman spectra (Figure S6) after reaction with ethanol showed $\mathrm{D}$ and $\mathrm{G}$ bands at 1380 and $1600 \mathrm{~cm}^{-1}$, respectively. The presence of an intense $\mathrm{D}$ band suggests the formation of more defective carbonaceous structures, such as amorphous carbon. On the other hand, a fairly intense $\mathrm{G}$ band shows the formation of more organized carbon, such as graphite and carbon nanotubes (CNT). The materials show an asymmetric $\mathrm{G}$ peak at $c a$. $1600 \mathrm{~cm}^{-1}$, which suggests the 


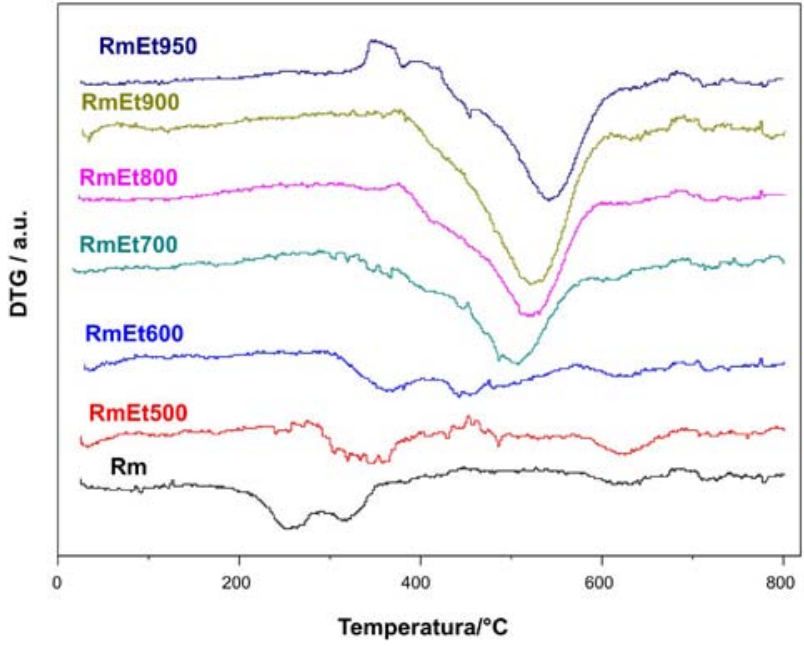

Figure S5. DTG curves for red mud and RmEt500, 600, 700, 800, 900 and 950 composites.

presence of single walled CNT (SWCNT). The G peak of multi-walled CNT (MWCNT) appears at $1580 \mathrm{~cm}^{-1}$, the same position reported for the graphite $\mathrm{G}$ band. For the materials prepared at higher temperatures, the $G$ band clearly presents two components. The components known as $\mathrm{G}+$ are related to atomic displacements along the tube axis, and those called G- to modes with atomic displacement along the circumferential direction. A series of bands related to the different oxides, e.g., oxides of Fe, $\mathrm{Si}, \mathrm{Al}$ and Ti present in the RM, can also be observed in the Raman spectra (range 100-1800 $\mathrm{cm}^{-1}$ ). Upon reaction with ethanol at $600^{\circ} \mathrm{C}$, no significant change in these bands was noticed. On the other hand, upon reaction at $700{ }^{\circ} \mathrm{C}$ new bands at 146, 170 and $200 \mathrm{~cm}^{-1}$ were observed. These bands are likely RBM modes ${ }^{28}$ related to the formation of single walled carbon nanotubes. These SWCNT present

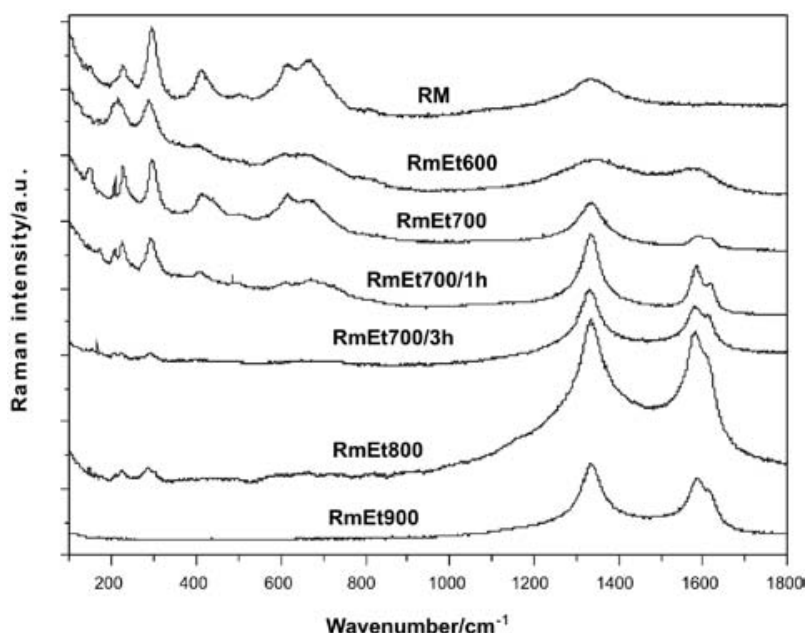

Figure S6. Raman spectra registered for pure red mud (RM) and for the RmEt600, 700, 700/1 h, 700/3 h, 800 and $900{ }^{\circ} \mathrm{C}$ samples. diameters from 1.0 to $1.6 \mathrm{~nm}$, calculated according to the equation $\omega_{\mathrm{RBM}}=227.0 / \mathrm{d}_{\mathrm{t}}$.

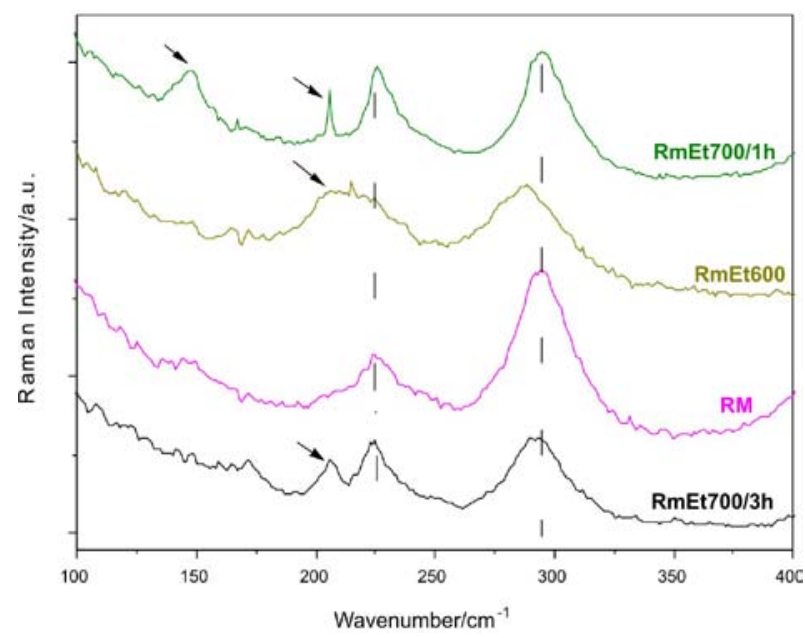

Figure S7. Raman spectra at low frequencies for samples RM, RmEt600, $700 / 1 \mathrm{~h}$ and $700 / 3 \mathrm{~h}$

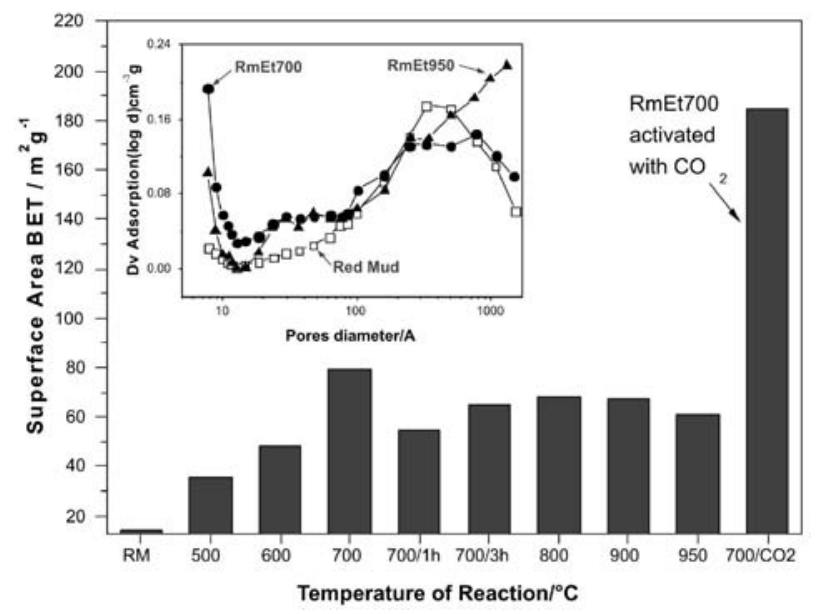

Figure S8. Surface area (BET) values and pore diameters for pure RM and products of TPCVD with ethanol at different temperatures.

The magnetic composites were dispersed in water by sonication for $5 \mathrm{~min}$ and the decantation of the particles was followed by a simple measurement of light transmittance in three different wavelengths $\left(450,600\right.$ and $\left.750 \mathrm{~cm}^{-1}\right)$. The results are displayed in Figure S9.

It can be observed for pure red mud that the solid particles remained stable in suspension. On the other hand, for the sample RmEt700, a rapid sedimentation was observed, reaching $38 \%$ of light retention within $c a$. $10 \mathrm{~min}$. As the TPCVD temperature increased to 800 and $900{ }^{\circ} \mathrm{C}$, the sedimentation rate increased. After $c a .15 \mathrm{~min}$ all suspensions seemed stable. All the remaining material in suspension was magnetic, and a simple approximation of a magnet removed all particles from the suspension 


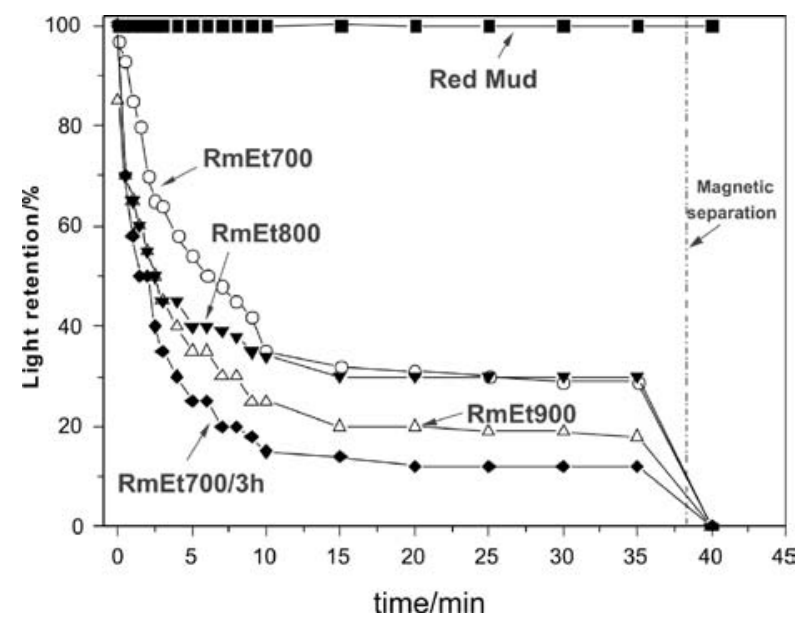

Figure S9. Deposition profile of RM and samples RmEt700, 700/1 h, 800 and 900

(Figure S10). The amount of suspended particles was obtained by simple separation of the settled material from the suspension after $35 \mathrm{~min}$, followed by drying overnight and weighting. The composites RmEt700, 700/3 h, 800 and 900 showed fractions of particles remaining in suspension of $c a .6,4,3$ and $5 \mathrm{wt} \%$, respectively.

The settled materials were analyzed by SEM and the images are shown in Figure S11.

Figure S11 suggests that ethanol TPCVD produced

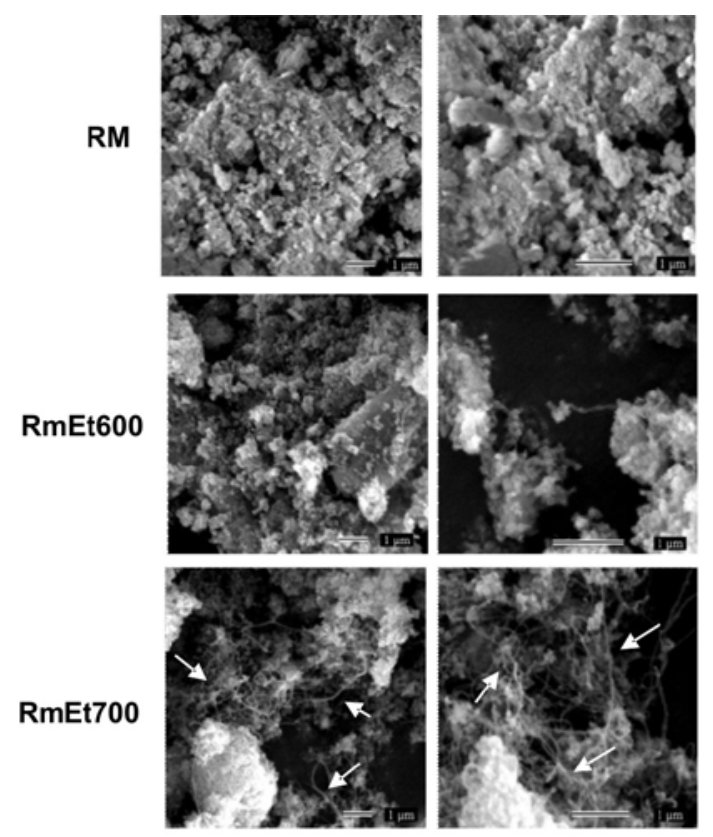

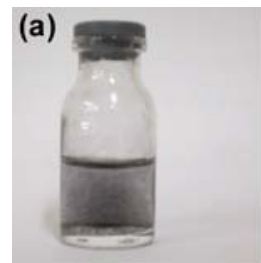

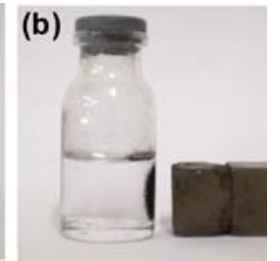

Figure S10. Magnetic particles in suspension (a) and their removal by a magnet (b).

large amount of filamentous carbon in all samples obtained above $700{ }^{\circ} \mathrm{C}$. The carbon filaments are in average $20 \mu \mathrm{m}$ long with diameters varying from 10 up to $100 \mathrm{~nm}$. EDS analysis after CVD showed the presence of different metals with a high concentration of carbon (Figure S12).

After dispersion in water, the material remaining in suspension was analyzed by SEM, showing aggregates of particles of 100-300 nm diameter and carbon filaments (Figure S13).

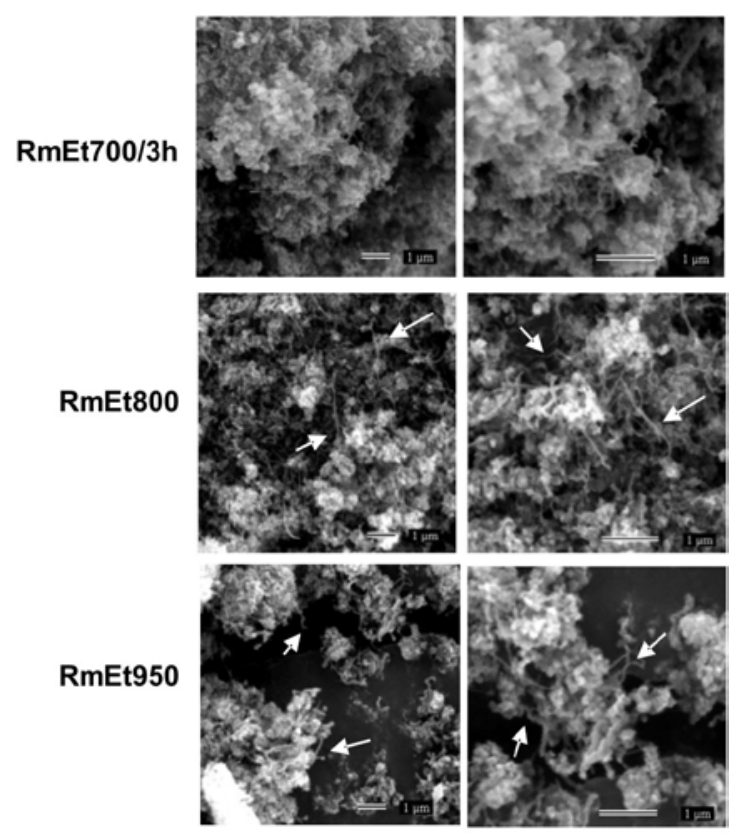

Figure S11. SEM images of RM and the magnetic composites after dispersion and settling in water. 


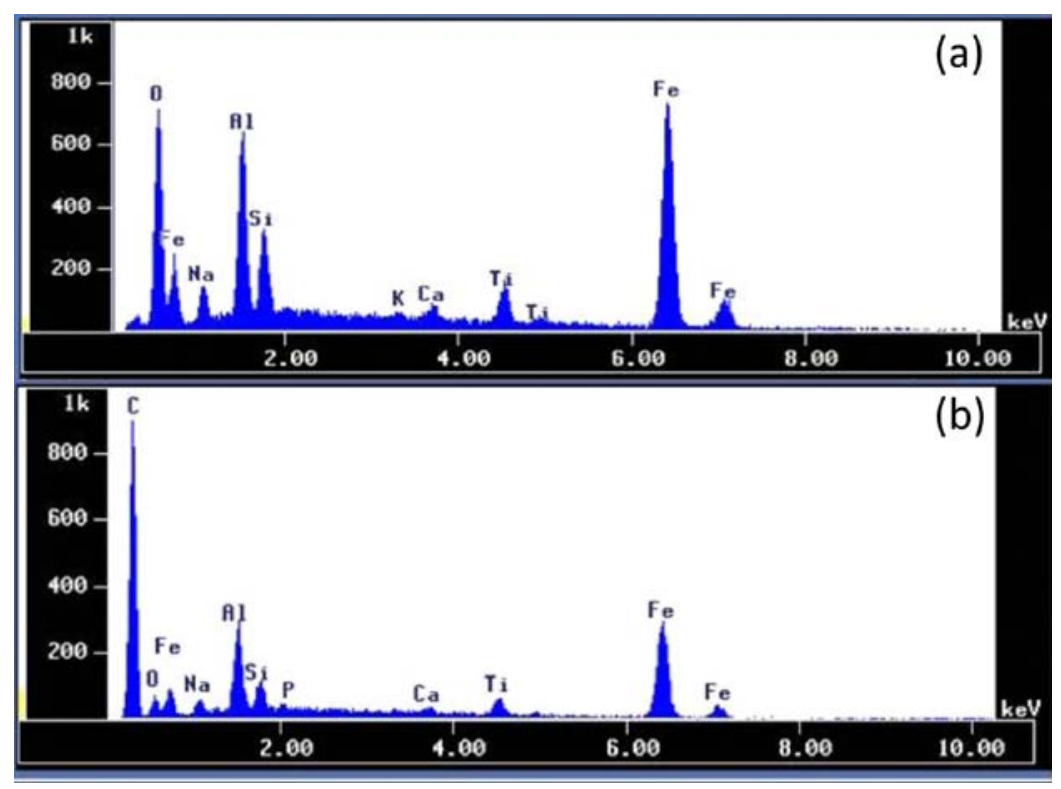

Figure S12. EDS microanalysis of (a) pure RM and (b) RmEt900.
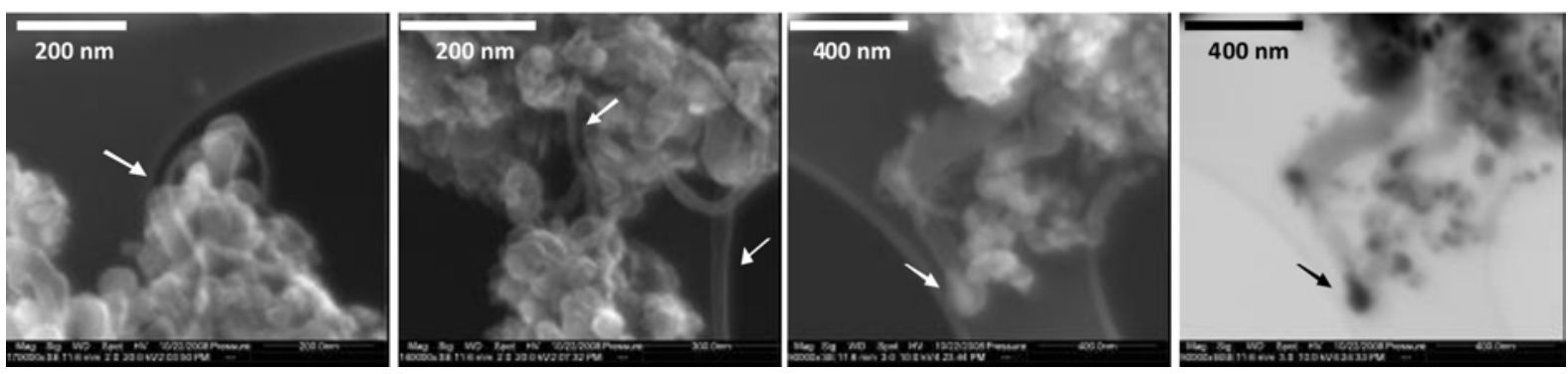

Figure S13. SEM images of the suspended material in sample RmEt700.

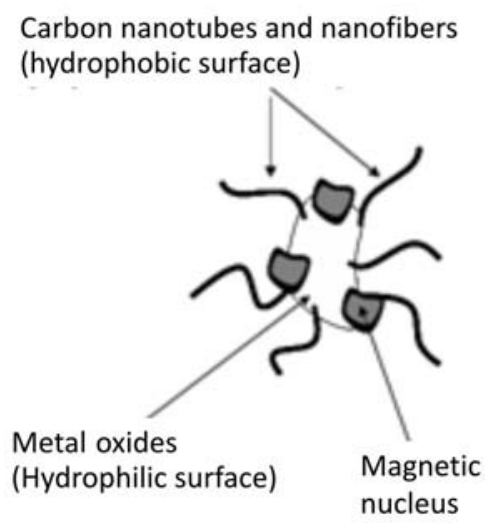

Figure S14. Scheme of the nanostructured, amphiphilic magnetic composite obtained from RM. 


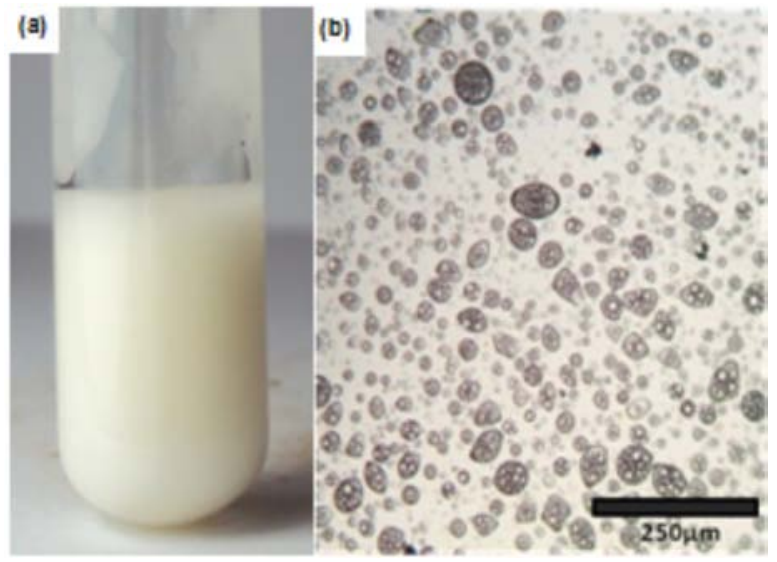

Figure S15. Emulsion of water 30\% v/v in biodiesel, (a) macro and (b) microscopic aspect.

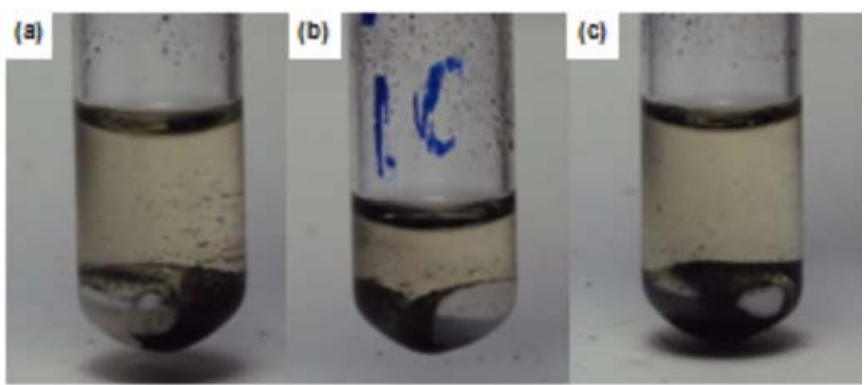

Figure S16. Images obtained after a demulsification test carried out for (a) RmEt600, (b) RmEt700 and (c) RmEt700/1 h, with 1000 ppm of the composites.
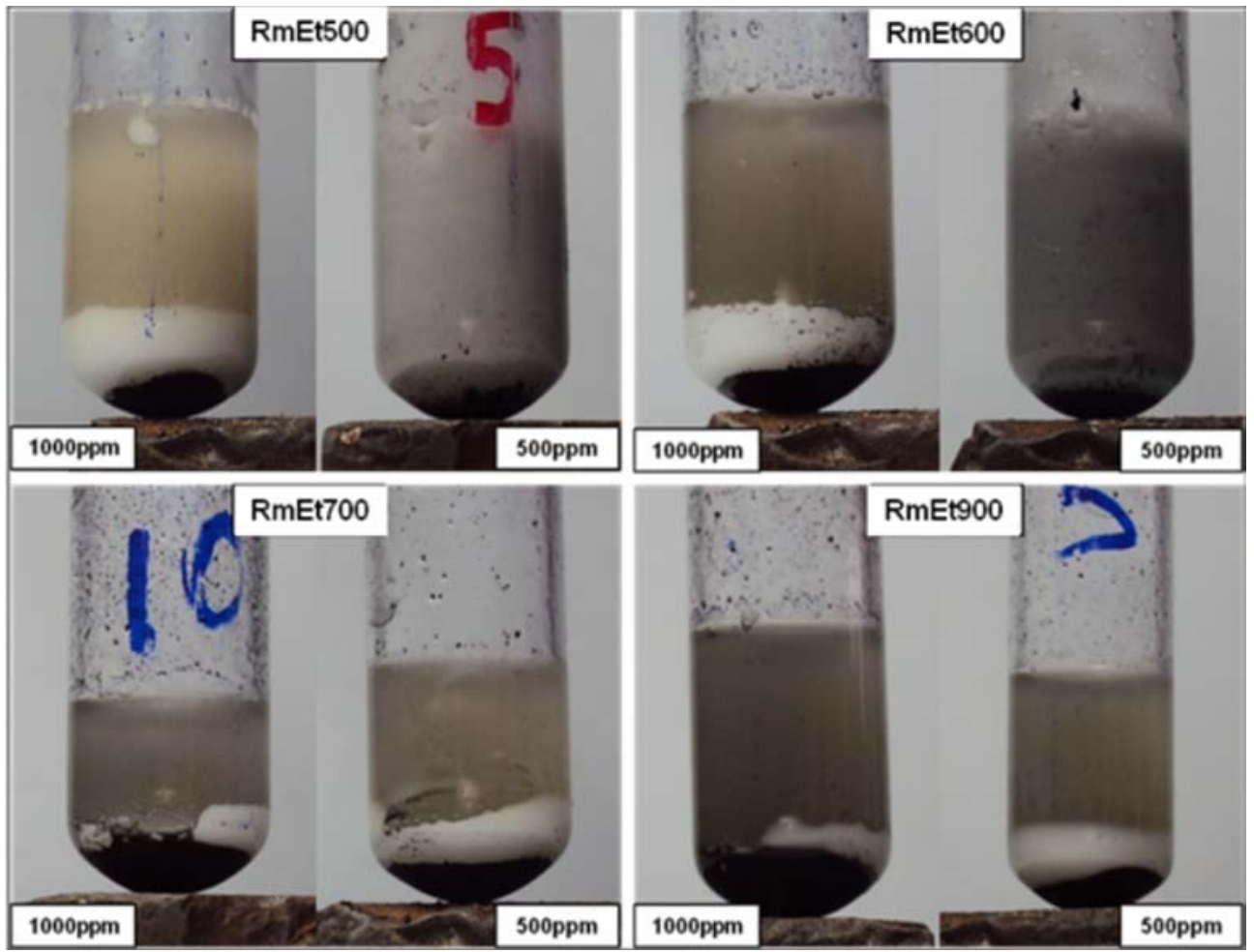

Figure S17. Emulsions with 1000 and 500 ppm of RmEt 500, 600, 700 and 900 after exposure to a magnetic field for 5 min. 


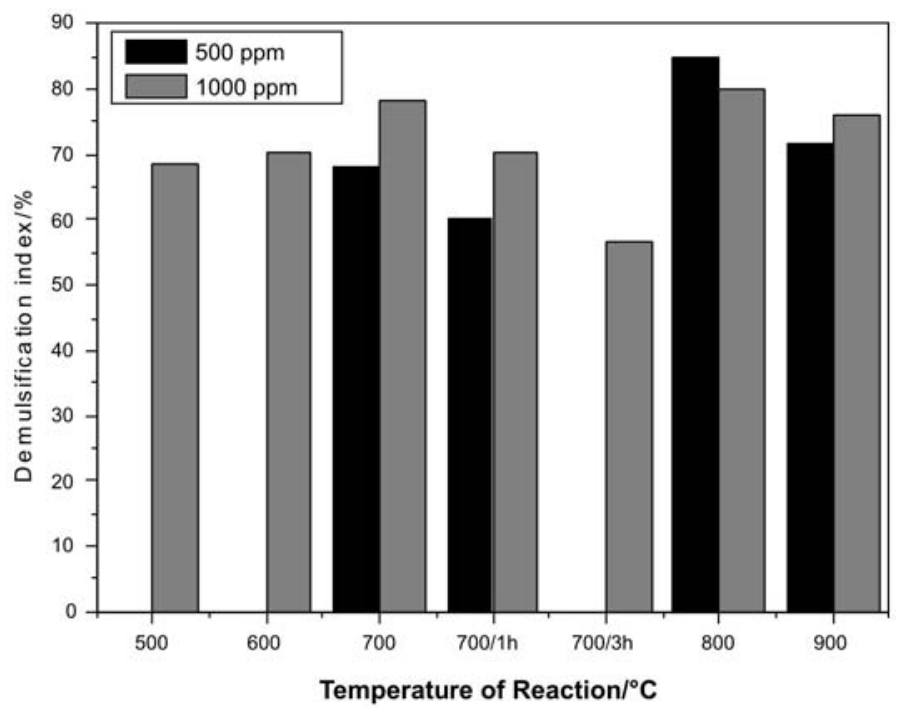

Figure S18. Demulsification index for the biodiesel/water emulsion with the composite described in this work. DI $=($ Demulsified Layer Height/Overall Height) $\times 100$.

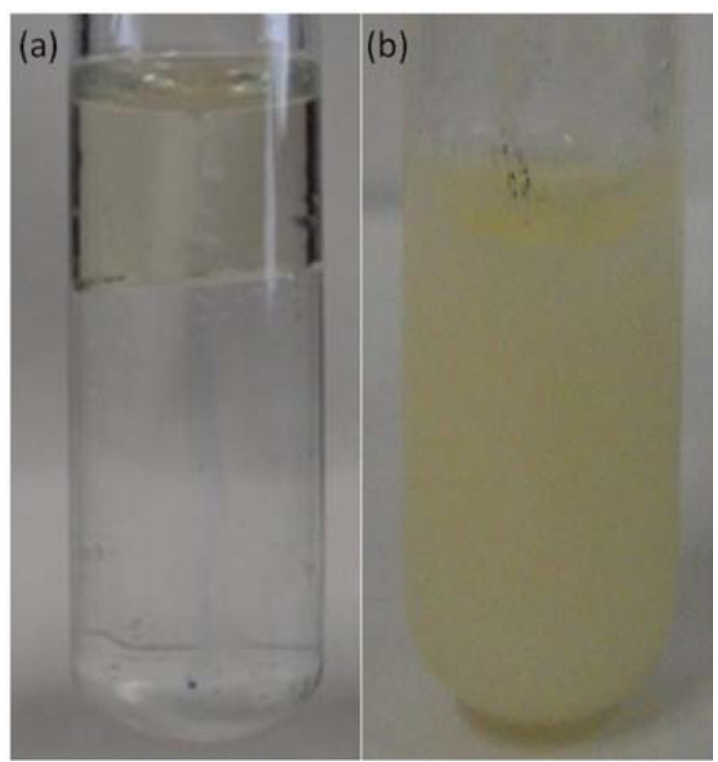

Figure S19. Macroscopic aspect of (a) water/soybean oil mixture and (b) stable emulsion formed with the emulsifier described in this work. 

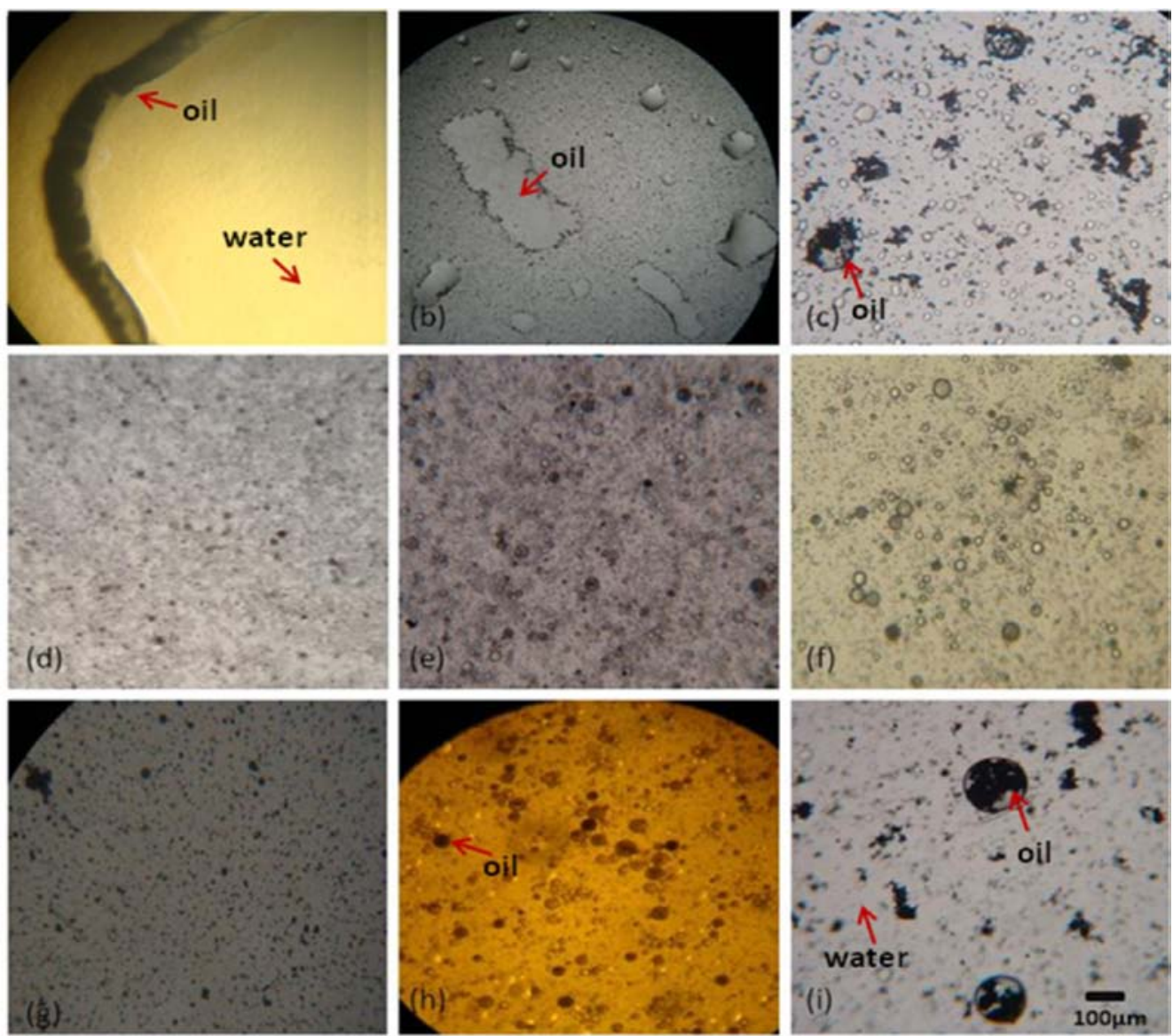

Figure S20. Microscopic images of (a) water and oil mixture and (b)-(i) emulsions formed with the amphiphilic composites prepared from red mud at different temperatures: (b) 500, (c) 600, (d) 700, (e) 700/1 h, (f) 700/3 h, (g) 800, (h) 900 and (i) $950{ }^{\circ} \mathrm{C}$.

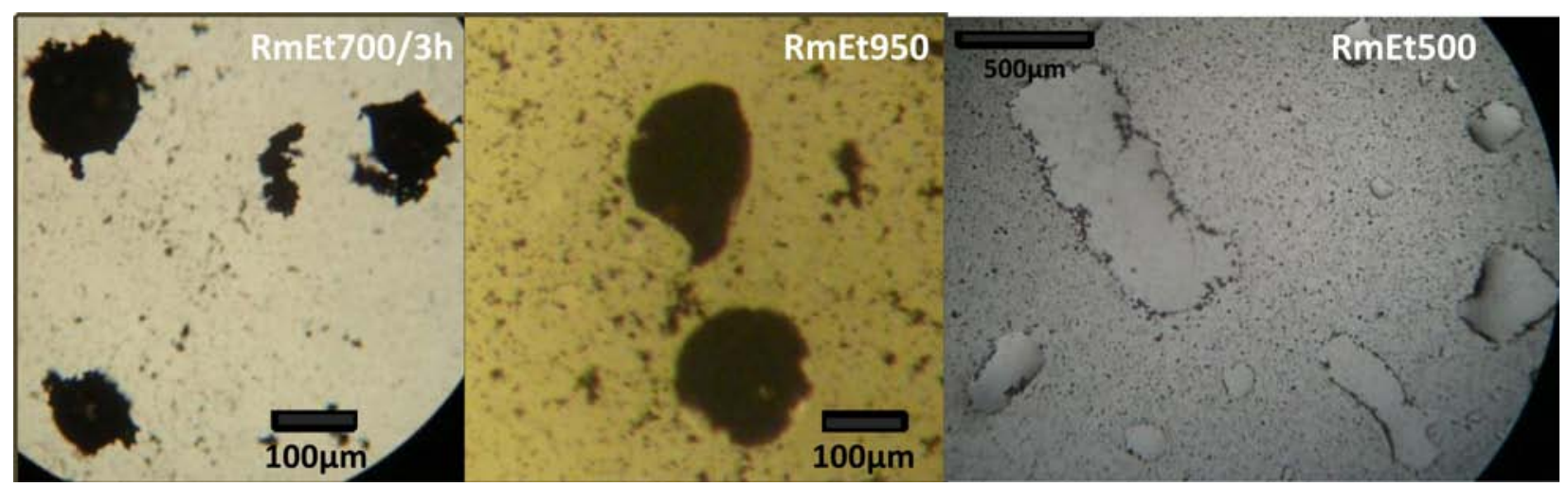

Figure S21. Different interactions of samples RmEt700/3 h, 950 and 500 on the oil/water interface. 


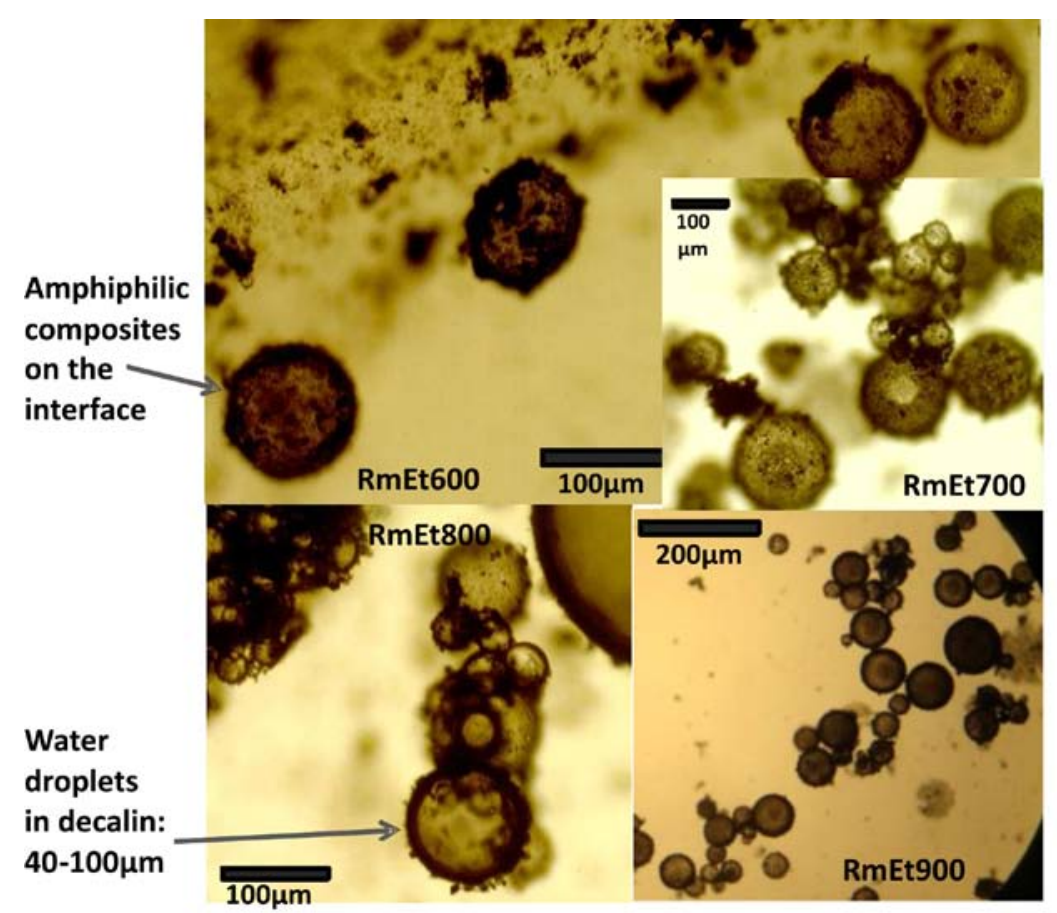

Figure S22. Microscopic images of emulsions formed with the amphiphilic composites prepared from RM at different temperatures: $600,700,800$ and $900^{\circ} \mathrm{C}$.
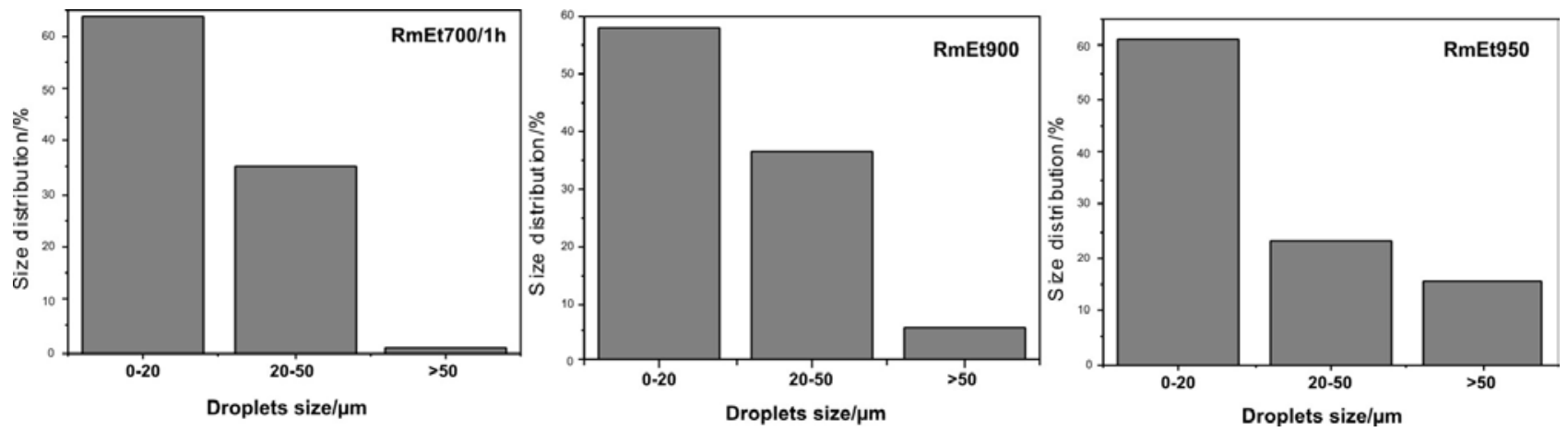

Figure S23. Droplet size distribution for emulsions formed by samples RmEt 700/1 h, 900 and 950. 